\title{
Cannabis as a substitute for prescription drugs - a cross-sectional study
}

\author{
James M Corroon Jr' \\ Laurie K Mischley² \\ Michelle Sexton ${ }^{3}$ \\ 'Center for Medical Cannabis \\ Education, Del Mar, CA, ${ }^{2}$ Bastyr \\ University Research Institute, \\ Kenmore, WA, ${ }^{3}$ Department of \\ Medical Research, Center for the \\ Study of Cannabis and Social Policy, \\ Seattle, WA, USA
}

This article was published in the following Dove Press journal: Journal of Pain Research

2 May 2017

Number of times this article has been viewed

Correspondence: James M Corroon Jr Center for Medical Cannabis Education, 428 8th Street, Del Mar, CA 920I4, USA Tel +l 8583670393

Email jamie@corroon.com
Background: The use of medical cannabis is increasing, most commonly for pain, anxiety and depression. Emerging data suggest that use and abuse of prescription drugs may be decreasing in states where medical cannabis is legal. The aim of this study was to survey cannabis users to determine whether they had intentionally substituted cannabis for prescription drugs.

Methods: A total of 2,774 individuals were a self-selected convenience sample who reported having used cannabis at least once in the previous 90 days. Subjects were surveyed via an online anonymous questionnaire on cannabis substitution effects. Participants were recruited through social media and cannabis dispensaries in Washington State.

Results: A total of 1,248 (46\%) respondents reported using cannabis as a substitute for prescription drugs. The most common classes of drugs substituted were narcotics/opioids (35.8\%), anxiolytics/benzodiazepines (13.6\%) and antidepressants (12.7\%). A total of 2,473 substitutions were reported or approximately two drug substitutions per affirmative respondent. The odds of reporting substituting were 4.59 (95\% confidence interval [CI], 3.87-5.43) greater among medical cannabis users compared with non-medical users and 1.66 (95\% CI, 1.27-2.16) greater among those reporting use for managing the comorbidities of pain, anxiety and depression. A slightly higher percentage of those who reported substituting resided in states where medical cannabis was legal at the time of the survey $(47 \%$ vs. $45 \%, p=0.58)$, but this difference was not statistically significant.

Discussion: These patient-reported outcomes support prior research that individuals are using cannabis as a substitute for prescription drugs, particularly, narcotics/opioids, and independent of whether they identify themselves as medical or non-medical users. This is especially true if they suffer from pain, anxiety and depression. Additionally, this study suggests that state laws allowing access to, and use of, medical cannabis may not be influencing individual decisionmaking in this area.

Keywords: cannabis, marijuana, prescription drugs, pain, analgesics, opioid

\section{Introduction}

The past two decades have brought about a prodigious change in state laws and social policies regarding the use of cannabis for medical and other purposes. Twenty-eight states and the District of Columbia currently enforce legalized medical cannabis laws. Eight of these states and the District of Columbia have also legalized cannabis for recreational use. ${ }^{1}$ Among other factors, these legislative and policy changes have resulted in shifts in social acceptance and cannabis use patterns in the US population, some of which have been driven by a growing understanding of the medicinal value of cannabis. ${ }^{2}$ 
According to the Center for Behavioral Health Statistics and Quality (CBHSQ), past-month use of cannabis has risen steadily each year in the general population from $5.8 \%$ in 2007 to $8.4 \%$ in 2014. In 2015, an estimated 22.2 million of $>265$ million Americans aged $\geq 12$ years reported having used cannabis in the past month (8.3\%). ${ }^{3}$

In addition to changing use patterns, recent research suggests that physicians' drug prescribing patterns may also be changing in states with legalized medical cannabis. Bradford and Bradford ${ }^{4}$ reported a drop in filled prescriptions in such states between 2010 and 2013 for drugs under Medicare Part D for the treatment of conditions such as pain, anxiety, depression and others. The US Centers for Disease Control and Prevention (CDC) has issued federal guidelines on the long-term use of opiates, noting concerns that there may be negative unintended consequences associated with dose reduction, such as patients switching to the use of heroin. ${ }^{5} \mathrm{An}$ alternative for patients with chronic pain is switching to the use of cannabis to navigate dose reduction and to treat their pain and/or comorbid conditions outright. ${ }^{6}$ A recent open-label, prospective study suggests that medical cannabis may decrease opioid use and benefit patients with treatment-resistant pain. ${ }^{7}$

Here, we analyzed self-reported data for frequency of prescription drug substitution with cannabis use across sociodemographic characteristics, prescription drug class, state legalization policies for medical cannabis and global quality of life health scores.

\section{Methods}

\section{Survey}

The institutional review board (IRB) of Bastyr University approved the protocol. Procedures were in accordance with the ethical standards of the Declaration of Helsinki, as revised in 2008. Documentation of consent was waived in accordance with Department of Health \& Human Services regulation 45 CFR 46.117(c) by the IRB of Bastyr University on the basis that the research presents no more than minimal risk of harm. The only record linking the subject with the research would be the consent document, and thus, the principal risk would be potential harm resulting from a breach of confidentiality. A literature review was conducted to identify existing epidemiological surveys of cannabis use. ${ }^{8-13}$ The authors developed a novel questionnaire by assessing the strengths and weaknesses of existing surveys to meet the goals of this study. Drafts were circulated to physician researchers and cannabis users for feedback in an iterative process. The final survey consisted of 44 structured questions answered by yes/no, multiple choice, open-ended response fields and rating scales. ${ }^{14}$ These included patientreported outcomes (PROs) using the PROMIS ${ }^{\circledR}$ Global Health 10-item short form (part of a National Institutes of Health $[\mathrm{NIH}]$ initiative to produce validated, self-reported item banks for physical, mental, emotional and social health) to measure overall well-being. Study data were collected and managed using Research Electronic Data Capture (REDCap), a secure tool allowing participants to directly enter responses. ${ }^{15}$

Subjects were a self-selected convenience sample who accessed the survey through links posted on the Center for the Study of Cannabis and Social Policy and Bastyr University websites, a Facebook page, flyers in Washington State cannabis dispensaries or word of mouth from December 2013 to January 2016. Recruitment strategies included Bastyr University medical students circulating the survey through their own social media, by distributing IRB-approved fliers to local medical cannabis dispensaries in Washington State, through public lectures describing the questionnaire at King County Library Systems locations, in an article written for an online Cannabis magazine and through an article posted to an online group located at momswithms.org. The only inclusion criterion was having used cannabis at least once in the past 90 days. A total of 31 respondents from the 2,864 respondents were deemed ineligible and excluded based on this criterion. Another 14 were excluded for failure to answer the eligibility question. To minimize risk to participants, no identifying information was collected. Individuals were given the opportunity to provide a five-digit code that enabled repeat responses to be identified with only the first response analyzed. A total of $389(10.4 \%)$ individuals failed to provide this code and were included in the final analysis. A total of 45 repeat responders were identified and deleted, leaving a total of 2,774 eligible respondents. Individuals were told that they could skip any question(s) they did not wish to answer. Those who refused to provide a five-digit code were included based on the rationale that fear of lost anonymity is more likely to motivate response refusal than repeat participation.

\section{Data sources and measurement}

Prescription drug substitution was evaluated by asking survey respondents, "Have you ever used cannabis as a substitute for prescription drugs (yes/no)?" If the respondent answered in the affirmative, an open-ended response field was available with the instructions, "Please list prescription drugs that you have substituted cannabis for:".

If a specific number of prescription drugs were entered into the open-ended response field, values were coded as the 
number of drugs per category. For example, "opiate pain killers (Roxicet, Percocet, Vicodin) and benzos (Xanax)" was counted as three substitutions in the drug category of narcotics/opioids and one substitution in the drug category of benzodiazepines. If a specific number of prescription drugs were not entered, values were coded as the number of drug categories. For example, "opiates and pain killers, muscle relaxants, anti-anxiety meds and depression meds" was counted as one substitution for the following four drug categories: narcotics/opioids, muscle relaxants, anxiolytics and antidepressants.

All nonspecific drug entries mentioning "anxiety" (e.g., "anxiety meds") were categorized as anxiolytics and then combined with drugs in the benzodiazepines category to form the broader category of anxiolytics/benzodiazepines. Combination drugs were recorded in multiple categories where appropriate, except for combinations of opioids and non-steroidal anti-inflammatory drugs (NSAIDs). Generic values like "pain medicine" were categorized as narcotics/ opioids, as opposed to NSAIDs/non-opioid analgesics. Generic values like "prescription headache medication" were categorized as anti-migraine, despite the absence of language confirming the headaches were actually migraines.

Drugs available over the counter (OTC), and entered with specific names, were recorded as prescription drugs. For example, "ibuprofen" was assumed to be prescription ibuprofen, given the nature of the question(s) in the survey.

Type of cannabis use was determined by asking the question, "What kind of user do you consider yourself to be?" Respondents were given four, non-mutually exclusive options: "recreational user", "medically indicated, recommended by licensed provider", "medically indicated, selfprescribed" and "religious (e.g., Rastafari)". For the purposes of this analysis, medical cannabis users were defined as those respondents identified as either "medically indicated, recommended by licensed provider" or "medically indicated, self-prescribed", including those who were also identified as a "recreational user".

\section{Data analyses}

Data analyses were conducted using SAS University Edition (SAS 9.4; SAS Institute Inc., Cary, NC, USA). Univariate and bivariate comparisons were conducted using PROC FREQ and chi-square tests. Odds ratios (ORs) were used to estimate strength of association using PROC LOGISTIC. Patient-Reported Outcomes Measurement Information
System (PROMIS) scores were calculated using the recommended scoring method that calibrates each score to a US national mean of 50 and standard deviation (SD) of $10 .{ }^{16}$ T-scores were calculated for only those respondents who answered all questions of the short form. Mean differences between PROMIS mental health and PROMIS physical health scores were computed using a two-sample $t$-test using PROC TTEST. Statistical significance was assessed using an alpha value of 0.05 . Figures were produced using Microsoft Excel for Mac, version 15.27.

\section{Results}

\section{Demographics}

A total of 2,774 respondents were included in the final study population. A majority of respondents were males $(55.72 \%)$, aged $<36$ years $(62.71 \%)$, Caucasian $(86.13 \%)$, residing in the US $(83.02 \%)$ and identifying themselves as medical cannabis users (59.81\%; Table 1). All 50 US states and $>42$ countries were represented in the survey. Just over half of respondents reported residing in the following states: Washington (32.50\%), California (8.47\%), Oregon (5.89\%) or Colorado (4.27\%).

A total of 1,248 respondents, or $\sim 46 \%$ of respondents, responded affirmatively to the question, "Have you ever used cannabis as a substitute for prescription drugs?" The odds of reporting substituting cannabis for prescription drugs increased with age, up to 65 years of age (Table 2). The odds of reporting substituting were 1.21 (95\% confidence interval [CI], 1.04-1.40) greater among females than males and 1.58 (95\% CI, 1.00-2.48) greater among Native American/Asian/ Pacific Islanders than Caucasians. Geographically, the odds of reporting substituting were greater among those residing in Canada (OR, 1.20; 95\% CI, 0.82-1.76) and lesser among those residing in Europe (OR, 0.93; 95\% CI, 0.72-1.21) as compared to those residing in the US. These geographical comparisons were not statistically significant.

\section{Substitution for prescription drugs}

A total of 1,248 respondents reported a total of 2,473 substitutions of prescription drugs. This represents approximately two drug substitutions per affirmative respondent. The most common classes of drugs substituted were narcotics/ opioids (35.8\%), anxiolytics/benzodiazepines (13.6\%) and antidepressants (12.7\%; Figure 1). Substituting cannabis for narcotics/opioids was 2.6 times more frequent than substituting cannabis for anxiolytics/benzodiazepines, the second most commonly substituted drug category. 
Table I Sociodemographic characteristics of survey respondents during $2016(n=2,774)$

\begin{tabular}{|c|c|}
\hline Characteristic & n (\%) \\
\hline \multicolumn{2}{|l|}{ Gender } \\
\hline Male & $\mathrm{I}, 529(55.72)$ \\
\hline Female & $\mathrm{I}, 2 \mathrm{I} 5(44.28)$ \\
\hline Missing & 30 \\
\hline \multicolumn{2}{|l|}{ Income: last 12 months } \\
\hline$<\$ 20,000$ & $548(20.45)$ \\
\hline$\$ 20,000-40,000$ & $644(24.03)$ \\
\hline$\$ 40,000-60,000$ & $456(17.01)$ \\
\hline$\$ 60,000-80,000$ & $298(11.12)$ \\
\hline$\$ 80,000-100,000$ & $258(9.63)$ \\
\hline$\$ 100,000-150,000$ & $268(10.00)$ \\
\hline$>\$ 150,000$ & $208(7.76)$ \\
\hline Missing & 94 \\
\hline \multicolumn{2}{|c|}{ Highest level of education } \\
\hline Less than eighth grade & $9(0.33)$ \\
\hline Grade 9-1I & $90(3.28)$ \\
\hline High school/GED & $771(28.14)$ \\
\hline Technical school & $307(11.20)$ \\
\hline Associate & $404(14.74)$ \\
\hline Bachelors & $793(28.94)$ \\
\hline Masters & $234(8.54)$ \\
\hline Doctorate & $132(4.82)$ \\
\hline Missing & 34 \\
\hline \multicolumn{2}{|l|}{ Age (years) } \\
\hline$\leq 21$ & $453(16.62)$ \\
\hline $22-35$ & I,256 (46.09) \\
\hline $36-50$ & $601(22.06)$ \\
\hline $5 I-65$ & $361(13.25)$ \\
\hline$>65$ & $54(1.98)$ \\
\hline Missing & 49 \\
\hline \multicolumn{2}{|l|}{ Current employment } \\
\hline Full time & I,425 (52.10) \\
\hline Part time & $577(21.10)$ \\
\hline Unemployed & $372(13.60)$ \\
\hline Retired & $116(4.24)$ \\
\hline Disabled & $245(8.96)$ \\
\hline Missing & 39 \\
\hline \multicolumn{2}{|l|}{ Race/ethnicity } \\
\hline Caucasian & $2,354(86.13)$ \\
\hline Black/African-American & $45(1.65)$ \\
\hline Hispanic & $99(3.62)$ \\
\hline Native American & $36(1.32)$ \\
\hline Asian/Pacific Islander & $43(1.57)$ \\
\hline Other & $156(5.7 \mathrm{I})$ \\
\hline Missing & 41 \\
\hline \multicolumn{2}{|l|}{ Geography } \\
\hline US & $2,234(83.02)$ \\
\hline Canada & $110(4.10)$ \\
\hline Europe & $266(9.90)$ \\
\hline Other & $81(3.01)$ \\
\hline Missing & 83 \\
\hline \multicolumn{2}{|l|}{ Type of user } \\
\hline Medical & I,659 (59.8I) \\
\hline Non-medical & I,II5 (40.19) \\
\hline \multicolumn{2}{|c|}{ Have you ever used cannabis as a substitute for prescription drugs? } \\
\hline Yes & $\mathrm{I}, 248(45.55)$ \\
\hline No & $\mathrm{I}, 492(54.45)$ \\
\hline Missing & 34 \\
\hline
\end{tabular}

Abbreviation: GED, General Educational Development.
Table 2 Odds of reporting ever having used cannabis as a substitute for prescription drugs by sociodemographic characteristics during $2016(n=2,740)$

\begin{tabular}{|c|c|c|c|}
\hline \multirow[t]{2}{*}{ Characteristic } & \multirow{2}{*}{$\begin{array}{l}\text { Yes }(n=I, 248) \\
n(\%)\end{array}$} & \multirow{2}{*}{$\begin{array}{l}\text { No }(n=1,492) \\
n(\%)\end{array}$} & \multirow[t]{2}{*}{ OR $(95 \% \mathrm{Cl})$} \\
\hline & & & \\
\hline \multicolumn{4}{|l|}{ Age (years) ${ }^{* * * *}$} \\
\hline$\leq 21$ & I85 (4I.29) & 263 (58.7I) & 1.00 (reference) \\
\hline $22-35$ & 542 (43.29) & 710 (56.7I) & $1.09(0.87-1.35)$ \\
\hline $36-50$ & $300(50.59)$ & $293(49.4 I)$ & $1.46(1.14-1.86)$ \\
\hline $51-65$ & $190(53.52)$ & 165 (46.48) & $1.64(1.24-2.17)$ \\
\hline$>65$ & $16(31.37)$ & $35(68.63)$ & $0.65(0.35-1.21)$ \\
\hline Missing & 15 & 60 & \\
\hline \multicolumn{4}{|l|}{ Gender* } \\
\hline Male & 661 (43.63) & 854 (56.37) & 1.00 (reference) \\
\hline Female & 581 (48.30) & $622(51.70)$ & $1.21(1.04-1.40)$ \\
\hline Missing & 6 & 50 & \\
\hline \multicolumn{4}{|l|}{ Race/ethnicity } \\
\hline Caucasian & $\mathrm{I}, 064(45.65)$ & I,267 (54.35) & 1.00 (reference) \\
\hline Black/African & $64(44.44)$ & $80(55.56)$ & $0.95(0.68-1.34)$ \\
\hline \multicolumn{4}{|l|}{ American/ } \\
\hline \multicolumn{4}{|l|}{ Hispanic } \\
\hline Native American/ & $45(56.96)$ & $34(43.04)$ & $1.58(1.00-2.48)$ \\
\hline \multicolumn{4}{|l|}{ Asian/Pacific } \\
\hline \multicolumn{4}{|l|}{ Islander } \\
\hline Other & $65(42.48)$ & $88(57.52)$ & $0.88(0.63-1.22)$ \\
\hline Missing & 10 & 57 & \\
\hline \multicolumn{4}{|l|}{ Geography } \\
\hline US & $\mathrm{I}, 002(45.50)$ & $\mathrm{I}, 200(54.50)$ & 1.00 (reference) \\
\hline Canada & $55(50.00)$ & $55(50.00)$ & $1.20(0.82-1.76)$ \\
\hline Europe & 116 (43.77) & $149(56.23)$ & $0.93(0.72-1.21)$ \\
\hline Other & $40(50.00)$ & $40(50.00)$ & $1.20(0.77-1.87)$ \\
\hline Missing & 35 & 82 & \\
\hline \multicolumn{4}{|l|}{ Type of user } \\
\hline Non-medical & $269(24.43)$ & 832 (75.57) & 1.00 (reference) \\
\hline Medical & 979 (59.73) & $660(40.27)$ & $4.59(3.87-5.43)$ \\
\hline Missing & 0 & 0 & \\
\hline
\end{tabular}

Notes: $p$-values for the above comparisons were the result of chi-square analyses. $* p<0.05$ and $* * * p<0.001$.

Abbreviations: $\mathrm{OR}$, odds ratio; $\mathrm{Cl}$, confidence interval.

\section{Medical versus non-medical users}

The odds of reporting substituting were 4.59 (95\% CI, 3.87-5.43) times greater among self-identified medical cannabis users as compared to non-medical cannabis users. Approximately one-quarter (24.43\%) of non-medical users reported substituting cannabis for prescription drugs (Table 2).

The relationship between user type (ie, medical or nonmedical) and frequency of reported substitution was assessed independently for males and females and for different categories of age. The odds of substituting were more than six times greater (OR, 6.09; 95\% CI, 4.65-7.80) among female medical users than among female non-medical users. Similarly, the odds were 3.7 times (95\% CI, 2.91-4.57) greater among male medical users. A trend in the odds of substituting among medical users was also seen with increased age (Table 3). 


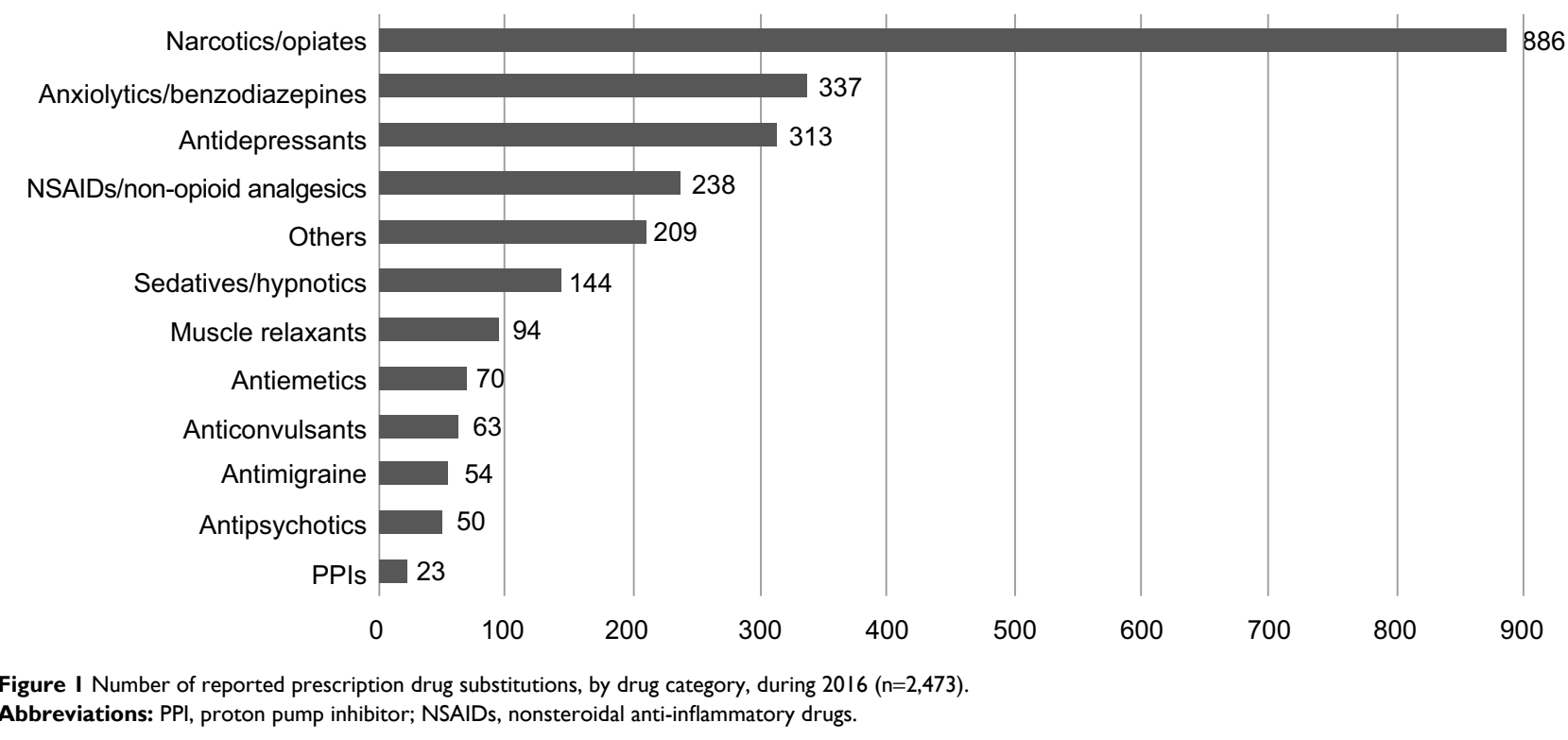

Table 3 ORs and $95 \% \mathrm{Cls}$ of reporting ever having used cannabis as a substitute for prescription drugs by user type, stratified by selected sociodemographic characteristics, during $2016(n=2,740)$

\begin{tabular}{ll}
\hline Characteristic & $\begin{array}{l}\text { Medical user, } \\
\text { OR (95\% Cl) }\end{array}$ \\
\hline $\begin{array}{l}\text { Gender } \\
\text { Female }\end{array}$ & $6.09(4.65-7.80)$ \\
Male & $3.67(2.91-4.57)$ \\
Age (years) & \\
$\leq 21$ & $4.79(3.20-7.18)$ \\
$22-35$ & $3.72(2.92-4.73)$ \\
$36-50$ & $5.32(3.63-7.78)$ \\
$5 I-65$ & $16.19(6.75-38.79)$ \\
$>65$ & NA \\
\hline
\end{tabular}

Notes: Reference, non-medical user. NA, insufficient data in one cell. Abbreviations: $\mathrm{OR}$, odds ratio; $\mathrm{Cl}$, confidence interval; $\mathrm{NA}$, not applicable.

\section{Comorbidities}

We previously reported in an earlier survey that of 1,429 respondents, $61 \%$ reported using cannabis for managing pain, $58 \%$ reported using cannabis for anxiety and 50\% reported using cannabis for depression. ${ }^{6}$ In the current analysis, these same conditions were also the most commonly reported conditions by respondents. Of the 1,040 participants reporting pain and/or intractable pain, 619 (59.52\%) reported depression and anxiety as comorbidities. As such, the odds of reporting substituting cannabis for prescription drugs were more than one and a half times greater (OR, 1.66; 95\% CI, 1.27-2.16) among those reporting using it to manage pain, anxiety and depression than among those using it to manage only one of the three conditions.

\section{States with legalized medical marijuana}

A slightly higher percentage of those who reported substituting resided in states where medical cannabis was legal at the time of the survey ( $47 \%$ vs. $44 \%, p=0.47$ ). This difference was not statistically significant.

\section{PROMIS Global Health}

The 10-item short form developed and published by PROMIS was used to arrive at a bottom-line indicator of self-reported health status. By summing the physical and mental health scores separately (using only participants with complete data on each subscale), the standard PROMIS raw score to T-score conversion allowed for comparing our sample with the general population. The distributions are standardized such that a score of 50 represents the mean for the US general population, with an SD of 10 points. A total of 1,186 respondents $(43 \%)$ provided complete information for the 10 -item short form. For mental health, the sample scored $39.34(\mathrm{SD}=5.05 ; 95 \% \mathrm{CI}, 39.15-39.53)$. For physical health, the sample scored 40.26 ( $\mathrm{SD}=3.94 ; 95 \% \mathrm{CI}, 40.11-40.41$ ), placing these respondents below average for global mental health and global physical health as compared with the general population. Those reporting substituting cannabis for prescription drugs scored similar to the overall sample population (mental health, mean: 39.75 [SD $=5.32 ; 95 \% \mathrm{CI}$, 39.45-40.05]; physical health, mean: 39.80 [SD $=4.00 ; 95 \%$ CI, 39.57-40.02]). In terms of the PROMIS raw scores (i.e., non-T-score-converted scores), those who reported substituting had slightly higher mental health scores (mean difference: $0.31 ; p<0.001)$ and slightly lower physical health scores 
(mean difference: $-0.31, p<0.001$ ) than those who denied substituting (Figure 2).

\section{Sensitivity analysis}

A total of 389 respondents failed to provide a 5-digit code anonymously identifying themselves as unique respondents. When excluded from the analysis, the percentage of respondents reporting ever using cannabis as a substitute for prescription drugs increased from $45.55 \%(n=1,248)$ to $46.28 \%(n=1,094)$, an increase of $1 \%$.

The odds of reporting substituting among medical users versus non-medical users decreased from 4.59 (95\% CI, $3.87-5.43)$ to 4.54 (95\% CI, 3.78-5.45), a decrease of $1.5 \%$. Finally, while the total number of prescription drug substitutions by drug category decreased from 2,473 to 2,160 , the per respondent substitution ratio remained two substitutions per respondent.

\section{Discussion}

The purpose of this study was to examine whether, and how often, cannabis users report substituting cannabis for prescription drugs. Overall, these PROs underscore four key points: 1) individuals are substituting cannabis for prescription drugs, independent of whether they identify themselves as medical users (medical users are doing so at almost five times the odds of non-medical users) and independent of legal access to medical cannabis; 2) this practice increases in frequency with age, up to 65 years, and is more common in females, particularly female medical users, and Native American/Asians/Pacific Islanders; 3) the most common classes of substitution were narcotics/opioids, anxiolytics/ benzodiazepines and antidepressants; and 4) the odds of reporting substituting cannabis for prescription drugs were more than one and a half times greater among those reporting the use of cannabis to manage pain, anxiety and depression than among those using it to manage only one of these three conditions. Stated differently, pain, anxiety and depression seem to represent a comorbidity triad that is associated with greater substitution frequency.

These data are in line with previous research suggesting that cannabis is commonly used as a substitute for prescription drugs. For example, in 2013 and 2016, Lucas et al ${ }^{17,18}$ found that $68 \%$ of 259 and $87 \%$ of 410 physician-authorized medical cannabis users in Canada reported substituting cannabis for alcohol and illicit or prescription drugs, respectively. In 2017, Lucas and Walsh ${ }^{19}$ found that $63 \%$ of 271 such subjects reported substituting cannabis for prescription drugs such as opioids (30\%), benzodiazepines (16\%) and antidepressants $(12 \%)$, representing the same top three categories as data presented here. These findings also agree with our previous data showing that medical cannabis users report using cannabis most frequently to manage pain, anxiety and depression. ${ }^{6}$ The present study contributes to a greater understanding of substitution across specific classes of prescription drugs in a largely US-based sample, in a much larger cohort and cross-section, occurring among both medical and nonmedical subjects, and in areas without legal access.

While the results of research on the effects of cannabis for medical use have been largely mixed, our previous study indicated that patients reporting using cannabis for managing pain are experiencing adequate symptom relief. ${ }^{6}$ In 2016 , Boehnke et al conducted a survey at a medical cannabis dispensary and found a $64 \%$ decrease in opioid use among those reporting using cannabis for chronic pain $(n=118)$. Respondents also reported a reduction in other classes of drugs, including antidepressants and NSAIDs, as well as a

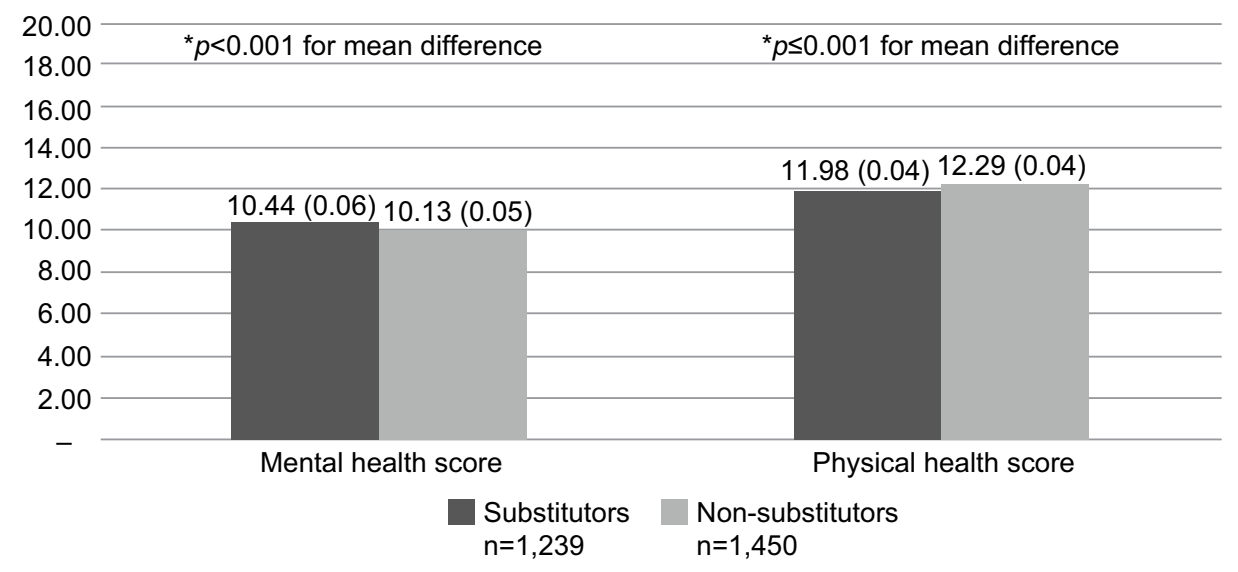

Figure 2 PROMIS Global Health short form: physical and mental health scores (mean [SE]; cannabis substitutors versus non-substitutors, 20I6; raw scores [i.e., non-T-score corrected]).

Notes: Maximum score $=20$ for each domain. High scores reflect better functioning.

Abbreviations: PROMIS, Patient-Reported Outcomes Measurement Information System; SE, standard error. 
decrease in the number of side effects of medications. ${ }^{20}$ This study highlights differences between those with the comorbidities of pain, anxiety and depression and those with only one of the morbidities.

This team previously reported that in a survey of 1,429 medical cannabis users, $61 \%$ reported cannabis use for pain, $58 \%$ reported cannabis use for anxiety and 50\% reported using cannabis to manage depression. ${ }^{6}$ In 2016, Dale and Stacey $^{21}$ reported that those using cannabis for pain were more likely to be substituting for prescription drugs. In 2017, Walsh et al published a review of medical cannabis and mental health to try to better understand how medical cannabis use may impact areas of potential concern for clinicians. "Relaxation and relief of anxiety" and "relief of negative mood" or depression were among the most widely reported conditions in 60 publications included in their analysis. ${ }^{22}$ Because it is common for chronic pain patients to be prescribed combinatorial pharmacotherapy to address comorbidity with depression and/or anxiety, it is largely unknown how often patients may be discontinuing prescription medications when initiating cannabis use. ${ }^{21}$ Doctors need to have open communication with their patients regarding these matters in order to ensure that the medical community does not repeat the prescribing mistakes made in the past with opioid pharmacotherapy, namely, unchecked use of medical cannabis that leads to adverse events and abuse. ${ }^{23}$ Furthermore, these preliminary data can serve to drive prospective research focused on whether cannabis can assist in opioid tapering protocols so that doctors can offer patients science-based guidance.

Importantly, older individuals may be substituting cannabis for prescription drugs at a higher rate than the general population, a finding in line with previous research. ${ }^{4}$ There are very little data on the impact of cannabis use in elderly populations. Our data show a trend toward increased substitution with age, perhaps not surprisingly, as older populations are more likely to be prescribed prescription drugs, particularly psychotropic medications. ${ }^{24,25}$

We previously reported that medical cannabis users are evaluating cannabis products for the presence of a secondary, non-intoxicating cannabinoid, cannabidiol (CBD), $\sim 40 \%$ of the time. ${ }^{6} \mathrm{CBD}$ does not have the same action at the cannabinoid receptor as $\Delta 9$-tetrahydrocannabinol (THC), the primary intoxicating constituent in cannabis. To avoid adverse effects, particularly in elderly populations, the application of CBD-dominant cannabis varietals and preparations may be warranted. There is a need for more research on mental health disorders and cannabis use, particularly with a focus on CBD rather than THC-dominant cannabis..$^{22}$ This information is needed for doctors to be able to adequately participate in conversations with their patients, regardless of age, about the role that medical cannabis may play in managing mental health conditions. ${ }^{26}$

We previously reported on gender differences in cannabis use and effects, highlighting the need for focused research on this topic. ${ }^{27}$ Importantly, there is evidence of differences in endocannabinoid system function across gender. ${ }^{28-30} \mathrm{Here}$, we report that female users may be more likely to substitute cannabis than male users (OR, 1.21; 95\% CI, 1.04-1.40) and that female medical users may be much more likely to substitute cannabis than female non-medical users (OR, 6.09; $95 \% \mathrm{CI}, 4.65-7.80)$. These findings are interesting given that females reported significantly less frequency and quantity of use in our previous study. In that study, women were more likely to report use for anxiety, nausea, anorexia and migraine headaches than men. Taken together, these findings provide preliminary data for future studies on gender-based differences in cannabis use and effects.

This study showed a nonsignificant difference between the proportion of individuals reporting substituting cannabis for prescription drugs in states with legalized medical cannabis versus states where cannabis remains illegal ( $47 \%$ vs. $44 \%, p=0.47)$. This finding suggests that state laws allowing access to, and use of, medical cannabis may not be influencing individual decision making in this area. This finding is in contrast to other studies showing that the use of prescription drugs fell in states once medical cannabis laws were implemented. ${ }^{4}$ This finding has public health implications and should be explored further.

As compared with the general population, survey respondents scored below average for global mental health and global physical health on the PROMIS 10-item short form. This association deserves further attention to determine whether individuals with lesser mental/physical health are using cannabis as a medical therapy or whether cannabis use is negatively affecting mental/physical health.

Given the current nationwide epidemic of prescription opioid-related abuse, addiction and death, there is an urgent need for alternatives with efficacy and safer toxicology profiles. ${ }^{31}$ It is important to note that active "substitution" with cannabis may be a conscious decision to reduce harm caused by narcotics. ${ }^{32}$ Not only may opioid therapy prove ineffective for some patients but it may also induce serious adverse reactions that complicate management, including allodynia or opioid-induced hyperalgesia, also known as "paradoxical pain". ${ }^{33}$ Chronic pain is an "expensive" condition, both 
economically and socially, yet existing pharmacotherapeutic interventions are not always adequate. ${ }^{34-36}$ Taken with preclinical data on the role of the endocannabinoid system in stress, pain processing and immune homeostasis, it is clear that future investigation is warranted using controlled trials with human subjects to better understand the role that cannabis may play in treating pain, anxiety, depression and other conditions. ${ }^{37-46}$

\section{Limitations}

The study population was a self-selected convenience sample, and it is possible that individuals with favorable opinions of, and experiences with, cannabis are more likely to have responded to the questionnaire than those with negative opinions and experiences. This, when considered with the predominance of males, Caucasians and individuals aged $<35$ years, indicates that our sample may not be representative of the general population. In addition, PROs are subject to reporting bias. ${ }^{47,48}$

Another limitation of this study was the method by which prescription drug information was collected. The availability of an open-ended response field enabled narrative responses that made accurate categorization difficult. In some instances, this limitation may have resulted in undercounting. For example, a response of "a variety of SSRIs" was counted as one drug substitution in the drug category antidepressants. In other instances, it may have resulted in overcounting. For example, a response of "opiate pain killers (Roxicet, Percocet, Vicodin)" was counted as three substitutions in the drug category of narcotics/opioids, yet the respondent may have only substituted cannabis for "Vicodin" after previously trying "Roxicet" and "Percocet". Additionally, drugs that are available both OTC and via prescription (e.g., ibuprofen) were counted as prescription substitutions, given the nature of the question. The substitution count for these OTC drugs would be overestimated if these drugs were not prescribed.

Data for determining the proportion of individuals reporting substituting cannabis for prescription drugs in states with legal versus illegal medical cannabis policies were analyzed as of December 31, 2016. Several states may not have had legal medical cannabis policies at the time an individual completed the survey, but did have such policies at the time of analysis, which may falsely increase the proportion of those reporting substituting in states with legalized medical cannabis.

\section{Conclusion}

These data contribute to a growing body of literature suggesting cannabis, legal or otherwise, is being used as a substitute for prescription drugs, particularly prescription pain relievers. According to the CDC, 259 million prescriptions for pain relievers were written by health care providers in $2012 .{ }^{49}$ In 2015 , two million Americans aged $\geq 12$ years had a substance use disorder that involved prescription pain relievers. ${ }^{50}$ The CDC also reports that overdoses from prescription opioids are a "driving factor" in the increase in opiate overdose deaths over the past 15 years. Such deaths have more than quadrupled in the same time period with $>20,000$ overdose deaths attributable to prescription pain relievers alone. ${ }^{51}$

Despite the illegality of cannabis in many states and the lack of professional guidance on dosing, routes of delivery and inadequate standardization or quality control for medical use, individuals are taking it upon themselves to augment, or discontinue, US Food and Drug Administration (FDA)approved drugs in favor of a largely unregulated herbal one.

\section{Acknowledgment}

This study was supported by NIH NCCAM K01ATTA (LKM). PROMIS was funded with cooperative agreements from the NIH Common Fund Initiative.

\section{Disclosure}

The authors report no conflicts of interest in this work.

\section{References}

1. NCSL [webpage on the Internet]. State Medical Marijuana Laws. Available from: http://www.ncsl.org/research/health/state-medicalmarijuana-laws.aspx. Accessed January 13, 2017.

2. National Academies of Sciences, Engineering, and Medicine. The Health Effects of Cannabis and Cannabinoids. Washington, DC: National Academies Press; 2017.

3. Center for Behavioral Health Statistics and Quality. Results from the 2015 National Survey on Drug Use and Health: Detailed Tables Prevalence Estimates, Standard Errors, PValues, and Sample Sizes. Rockville, MD: Center for Behavioral Health Statistics and Quality; 2015.

4. Bradford AC, Bradford WD. Medical marijuana laws reduce prescription medication use in Medicare part D. Health Aff (Millwood). 2016;35(7):1230-1236.

5. Dowell D, Haegerich TM, Chou R. CDC guideline for prescribing opioids for chronic pain - United States, 2016. MMWR Recomm Rep. 2016;65(1):1-49.

6. Sexton M, Cuttler C, Finnell JS, Mischley LK. A cross-sectional survey of medical cannabis users: patterns of use and perceived efficacy. Cannabis Cannabinoid Res. 2016;1(1):131-138.

7. Haroutounian S, Ratz Y, Ginosar Y, et al. The effect of medicinal cannabis on pain and quality-of-life outcomes in chronic pain. Clin J Pain. 2016;32(12):1036-1043.

8. Walsh Z, Callaway R, Belle-Isle L, et al. Cannabis for therapeutic purposes: patient characteristics, access, and reasons for use. Int J Drug Policy. 2013;24(6):511-516.

9. Hazekamp A, Ware MA, Muller-Vahl KR, Abrams D, Grotenhermen F. The medicinal use of cannabis and cannabinoids - an international crosssectional survey on administration forms. J Psychoactive Drugs. 2013; 45(3):199-210. 
10. Webb CW, Webb SM. Therapeutic benefits of cannabis: a patient survey. Hawaii J Med Public Health. 2014;73(4):109-111.

11. Reinarman C, Nunberg H, Lanthier F, Heddleston T. Who are medical marijuana patients? Population characteristics from nine California assessment clinics. J Psychoactive Drugs. 2011;43(2):128-135.

12. Barnwell S, Earleywine M, Wilcox R. Cannabis, motivation, and life satisfaction in an internet sample. Subst Abuse Treat Prev Policy. 2006;1(1):2.

13. Reiman A. Medical cannabis patients: patient profiles and health care utilization patterns. Complement Health Pract Rev. 2007;12(1):31-50.

14. Survey of Cannabis Use, 2013. Available from: https://bastyr.edu/ research/studies/survey-cannabis-use.

15. Harris PA, Taylor R, Thielke R, Payne J, Gonzalez N, Conde JG. Research electronic data capture (REDCap) - a metadata-driven methodology and workflow process for providing translational research informatics support. J Biomed Inform. 2009;42(2):377-381.

16. Hays RD, Bjorner J, Revicki RA, Spritzer KL, Cella D. Scoring PROMIS global short form development of physical and mental health summary scores from the Patient Reported Outcomes Measurement Information System (PROMIS) global items Estimating EuroQoL (EQ-5D) Index Scores. Qual Life Res. 2009;18(7):873-880.

17. Lucas P, Reiman A, Earleywine M, et al. Cannabis as a substitute for alcohol and other drugs: a dispensary-based survey of substitution effect in Canadian medical cannabis patients. Addict Res Theory. 2013;21(5):435-442.

18. Lucas P, Walsh Z, Crosby K, et al. Substituting cannabis for prescription drugs, alcohol and other substances among medical cannabis patients: the impact of contextual factors. Drug Alcohol Rev. 2016;35(3):326-333.

19. Lucas P, Walsh Z. Medical cannabis access, use, and substitution for prescription opioids and other substances: a survey of authorized medical cannabis patients. Int J Drug Policy. 2017;42:30-35.

20. Boehnke KF, Litinas E, Clauw DJ. Medical cannabis use is associated with decreased opiate medication use in a retrospective crosssectional survey of patients with chronic pain. J Pain. 2016;17(6): 739-744.

21. Dale R, Stacey B. Multimodal treatment of chronic pain. Med Clin North Am. 2016;100(1):55-64.

22. Walsh Z, Gonzalez R, Crosby K, S Thiessen M, Carroll C, Bonn-Miller MO. Medical cannabis and mental health: a guided systematic review. Clin Psychol Rev. 2017;51:15-29.

23. Choo EK, Feldstein Ewing SW, Lovejoy TI. Opioids out, cannabis. JAMA. 2016;316(17):1763.

24. Ćurković M, Dodig-Ćurković K, Erić AP, Kralik K, Pivac N. Psychotropic medications in older adults: a review. Psychiatr Danub. 2016;28(1):13-24.

25. Liu GG, Christensen DB. The continuing challenge of inappropriate prescribing in the elderly: an update of the evidence. JAm Pharm Assoc (Wash). 2002;42(6):847-857.

26. Hill KP. Medical marijuana for treatment of chronic pain and other medical and psychiatric problems. JAMA. 2015;313(24):2474.

27. Cuttler C, Mischley LK, Sexton M. Sex differences in cannabis use and effects: a cross-sectional survey of cannabis users. Cannabis Cannabinoid Res. 2016;1(1):166-175.

28. Craft RM, Marusich JA, Wiley JL. Sex differences in cannabinoid pharmacology: a reflection of differences in the endocannabinoid system? Life Sci. 2013;92(8-9):476-481.

29. Fattore L, Fratta W. How important are sex differences in cannabinoid action? Br J Pharmacol. 2010;160(3):544-548.

30. Gorzalka BB, Dang SS. Minireview: endocannabinoids and gonadal hormones: bidirectional interactions in physiology and behavior. Endocrinology. 2012;153(3):1016-1024.

31. Wilkerson JL, Ghosh S, Mustafa M, et al. The endocannabinoid hydrolysis inhibitor SA-57: intrinsic antinociceptive effects, augmented morphine-induced antinociception, and attenuated heroin seeking behavior in mice. Neuropharmacology. 2017;114:156-167.
32. Lau N, Sales P, Averill S, Murphy F, Sato S-O, Murphy S. A safer alternative: cannabis substitution as harm reduction. Drug Alcohol Rev. 2015;34(6):654-659.

33. CHU L, CLARK D, ANGST M. Opioid tolerance and hyperalgesia in chronic pain patients after one month of oral morphine therapy: a preliminary prospective study. J Pain. 2006;7(1):43-48.

34. Giummarra MJ, Gibson SJ, Allen AR, Pichler AS, Arnold CA. Polypharmacy and chronic pain: harm exposure is not all about the opioids. Pain Med. 2015;16(3):472-479.

35. Phillips CJ. The cost and burden of chronic pain. Rev Pain. 2009;3(1):2-5.

36. Gaskin DJ, Richard P. The economic costs of pain in the United States. J Pain. 2012;13(8):715-724.

37. de Mello Schier AR, de Oliveira Ribeiro NP, Coutinho DS, et al. Antidepressant-like and anxiolytic-like effects of cannabidiol: a chemical compound of Cannabis sativa. CNS Neurol Disord Drug Targets. 2014;13(6):953-960.

38. Campos AC, Moreira FA, Gomes FV, Del Bel EA, Guimaraes FS. Multiple mechanisms involved in the large-spectrum therapeutic potential of cannabidiol in psychiatric disorders. Philos Trans $R$ Soc Lond B Biol Sci. 2012;367(1607):3364-3378.

39. Gomes FV, Resstel LBM, Guimarães FS. The anxiolytic-like effects of cannabidiol injected into the bed nucleus of the stria terminalis are mediated by 5-HT1A receptors. Psychopharmacology (Berl). 2011; 213(2-3):465-473.

40. Bhattacharyya S, Fusar-Poli P, Borgwardt S, et al. Modulation of mediotemporal and ventrostriatal function in humans by $\Delta 9$-tetrahydrocannabinol. Arch Gen Psychiatry. 2009;66(4):442.

41. Gaetani S, Dipasquale P, Romano A, et al. Chapter 5 the endocannabinoid system as a target for novel anxiolytic and antidepressant drugs. Int Rev Neurobiol. 2009;85:57-72.

42. Schier AR, Ribeiro NP, Silva AC, et al. Cannabidiol, a Cannabis sativa constituent, as an anxiolytic drug. Rev Bras Psiquiatr. 2012;34(suppl 1):S104-S110.

43. Lazary J, Eszlari N, Juhasz G, Bagdy G. Genetically reduced FAAH activity may be a risk for the development of anxiety and depression in persons with repetitive childhood trauma. Eur Neuropsychopharmacol. 2016;26(6):1020-1028.

44. Gray JM, Wilson CD, Lee TTY, et al. Sustained glucocorticoid exposure recruits cortico-limbic $\mathrm{CRH}$ signaling to modulate endocannabinoid function. Psychoneuroendocrinology. 2016;66:151-158.

45. Gobira PH, Almeida-Santos AF, Guimaraes FS, Moreira FA, Aguiar DC. Role of the endocannabinoid 2-arachidonoylglycerol in aversive responses mediated by the dorsolateral periaqueductal grey. Allergol Immunopathol (Madr). 2016;26(1):15-22.

46. Osborn LA, Lauritsen KJ, Cross N, et al. Self-medication of somatic and psychiatric conditions using botanical marijuana. $J$ Psychoactive Drugs. 2015;47(5):345-350.

47. Johnston BC, Patrick DL, Busse JW, Schünemann HJ, Agarwal A, Guyatt GH. Patient-reported outcomes in meta-analyses - part 1: assessing risk of bias and combining outcomes. Health Qual Life Outcomes. 2013;11:109.

48. Basch E, Bolt DM, Deng S, et al. The missing voice of patients in drug-safety reporting. N Engl J Med. 2010;362(10):865-869.

49. CDC [webpage on the Internet]. Opioid Painkiller Prescribing | Vital Signs | CDC. Available from: https://www.cdc.gov/vitalsigns/opioidprescribing/. Accessed February 1, 2017.

50. Center for Behavioral Health Statistics and Quality [webpage on the Internet]. Key substance use and mental health indicators in the United States: results from the 2015 National Survey on Drug Use and Health (HHS Publication No. SMA 16-4984, NSDUH Series H-51); 2016. Available from: http://www.samhsa.gov/data/. February 1, 2017.

51. Centers for Disease Control and Prevention, National Center for Injury Prevention and Control D of UIP [webpage on the Internet]. Understanding the Epidemic $\mid$ Drug Overdose $\mid$ CDC Injury Center; 2016. Available from: https://www.cdc.gov/drugoverdose/epidemic/. Accessed February $1,2017$. 
The Journal of Pain Research is an international, peer reviewed, open access, online journal that welcomes laboratory and clinical findings in the fields of pain research and the prevention and management of pain. Original research, reviews, symposium reports, hypothesis formation and commentaries are all considered for publication.
The manuscript management system is completely online and includes a very quick and fair peer-review system, which is all easy to use. Visit http://www.dovepress.com/testimonials.php to read real quotes from published authors. 